\title{
Commentary \\ Establishing a missing person DNA Biobank as a form of human rights protection
}

\author{
Eugenia Carnevali ${ }^{1, *}$, Simona Severini ${ }^{1}$, Gabriele Margiotta ${ }^{2}$, Martina Onofri ${ }^{1}$, \\ Cristiana Gambelunghe ${ }^{3}$, Luigi Carlini ${ }^{3}$, Mauro Bacci ${ }^{3}$
}

${ }^{1}$ Azienda Ospedaliera "S. Maria”, 05100 Terni, Italy

${ }^{2}$ Ospedale Regionale “S. Salvatore”, 67100 L’Aquila, Italy

${ }^{3}$ Dipartimento di Medicina e Chirurgia, Università degli Studi di Perugia, 06129 Perugia, Italy

*Correspondence: e.carnevali@aospterni.it (Eugenia Carnevali)

Academic Editor: Graham Pawelec

Submitted: 17 November 2021 Revised: 15 January 2022 Accepted: 18 January 2022 Published: 11 February 2022

\begin{abstract}
Nowadays, organ transplantation is considered an established medical practice that, every year, improves the quality of life of thousands of patients. However, the increasing demands for kidney transplantation are in contrast with the global lack of organs. The imbalance between supply and demand for organs has created the basis for a highly profitable black market, placing illicit organ trafficking in the broader context of human trafficking. Currently, thanks to the advancements of the analytical techniques used in laboratories, forensic genetics is able to discriminate the geographical origin of genetically distinct populations. The recent availability of genetic data regarding many populations of the world and the concomitant development of technologies and methodologies that are appropriate for the study of panels of STRs and SNPs are fundamental resources in this direction. This type of analyses, together with the creation of missing person DNA databases, may be used in cases of dubious origin of organs or in transplantation cases in which clear and comprehensive medical records of patients and donors are not available. It can also establish a scientific tool useful to contrast the illegal traffic of human kidneys. In this article, we will discuss biological and ethical aspects of this interesting perspective.
\end{abstract}

Keywords: kidney; transplantation; genetics; human trafficking; black market; single nucleotide polymorphisms; missing person DNA database

\section{Introduction}

Illicit organ trafficking is a part of the broader context of human trafficking, as clearly highlighted in the documents of the United Nations Office for Drugs Control and Crime Prevention (UNODC) [1,2]. The global report on trafficking in human beings lists several purposes that trafficking can serve and groups them into three categories:

a - exploitation of prostitution or other forms of sexual exploitation;

b - forced labour, slavery, or practices similar to slavery;

c - removal of organs.

Modalities in human trafficking have evolved over time and the 2018 UNODC report highlights a new and increasingly widespread practice of "fraudulent marriages". These arrangements have been defined as "exploitative sham marriages" by the EU "Hestia" [3] project, and they consist in fictitious marriages between individuals of European and non-European nationalities, or between European individuals, aimed at obtaining a permanent residence permit in a European country, financial or work benefits. Although these mock marriages differ from forced marriages, which lack the free consent of one or both of the individuals involved, they nonetheless represent a form of human exploitation. The "Hestia" project showed that some "ex- ploitative sham marriages" present all three elements of the crime of human trafficking: criminal organization, the use of force, and the intent of exploitation [3].

Criminals may work on their own in recruiting and trafficking victims, or they may operate within organised structures that use "recruiters" who have the task of identifying people potentially interested in contracting mock marriages. Such persons can be men from India, Pakistan, or Bangladesh to obtain EU residence permit, work, and citizenship benefits [1], and, at the same time, recruiters may persuade women from the Baltic States, Eastern Europe, Portugal, or France to move to the UK, Ireland or Germany to marry men they have never met with promises of money or lucrative work [3]. Traffickers generally, but not exclusively, target as potential victims women, often with poor backgrounds and minimal education, or from vulnerable populations or destitute communities, such as the Romani people [4].

Recruiters use personal and social media contacts on online platforms such as Facebook and internet dating sites and create targeted advertisements to lure potential victims with false promises of money, misleading information about job offers, housing or divorce proceedings, and other fraudulent opportunities [1-3]. Despite knowing the fictitious nature of the marriage, the victims do not receive the 
benefits they expected and find themselves trapped in a deceptive situation in a foreign country, where they live in fear and are subjected to forms of exploitation that range from sex trafficking to domestic servitude, to forced criminal activities [1,2].

These same tactics are employed by traffickers to prey on other particularly vulnerable groups, such as marginalised individuals, children, or undocumented migrants - the latter of whom make up a substantial portion of the victims of human trafficking detected worldwide [2] - to exploit them in other forms, other than mock marriages. Among them, there is sexual exploitation, forced labour, begging, and the aforementioned forced marriages $[1,2]$. These exploitative practices are extremely profitable [5] and some criminal networks run multimillion-dollar businesses where human trafficking is only part of a wider scheme involving other illegal activities, such as migrant smuggling and organ trafficking $[1,2,6,7]$.

\section{The emerging problem of illegal organ traffic and transplant tourism}

The growing demand for organ transplantations [8] and the improved medical and technical skills clash with the global lack of organs. It is estimated that the current rates of organ transplants satisfy less than $10 \%$ of the global necessity for organs [8], creating the basis for a highly profitable black market. As already mentioned, human trafficking is part of the broader context of organ trafficking, as recognised in the "Additional Protocol to the United Nations Convention against Organized Crime to Prevent, Suppress and Punish Trafficking in Persons, in particular Women and Children" (the so-called Palermo Protocol, published in 2000) [7]. Less than $1 \%$ of the detected human trafficking victims were exploited for organ removal [1,2], therefore, this form of exploitation may be perceived as marginal. However, incidents of trafficking harvesting have been officially observed in 25 countries [1], and it is estimated that $10 \%$ of the organ transplants performed worldwide make use of illegally sourced organs, meaning around 15000 solid organs transplant [8]. In addition, there is a concrete difficulty in accessing reliable data to be able to approximate the correct number of victims, given the illegal nature of these activities and given the unknown identity of the vulnerable individuals who are coerced into being organ donors or that willingly decide to sell their organs $[1,6,9-$ $12]$.

Indeed, organ trafficking was recognized as a significant humanitarian and health policy problem back in 1991, when the World Health Assembly called on states to prevent the purchase and sale of human organs for transplantation, with Resolution 44.25 [13], in 2000 with the aforementioned Palermo Protocol, and in 2004, when Governments of all countries were called upon "to take measures to protect the poorest and vulnerable groups from transplant tourism and from the sale of tissues and organs, emphasiz- ing the wider problem of the international trafficking of tissues and organs" (Resolution of the World Health Assembly 57.18) [14].

Additionally, the International Summit on Transplant Tourism and Organ Trafficking, held in Istanbul in 2008, resulted in the Istanbul Declaration on Organ Trafficking and Transplant Tourism [15], in which the terms "organ trafficking", "transplant trade" and "transplant tourism" are precisely defined.

In the 2015 Council of Europe Convention against Trafficking in Human Organs [16], the crimes related to the removal of human organs for purposes other than those included in the organ transplantation provisions of the country of origin are further reiterated.

"Organ trafficking" means the recruitment, transport, transfer, concealment or reception of living or deceased persons or their organs through threats, use of force or other forms of coercion or through kidnapping, fraud, deception, abuse of power or exploitation of a position of vulnerability [7]. It also means the offer or reception of payments or benefits from third parties to obtain control over the potential donor, for exploitation through the removal of organs for transplantation.

In fact, trafficking in human beings for the purpose of organ removal (THBOR) and trafficking in organs, tissues, and cells (OTC) are two very different, albeit interconnected, phenomena [7,17]. The major difference between the two lies in the objective: in the first case the person themselves are being trafficked, while in OTC traffic, the organs, tissues or cells are being commercialized. OTC trafficking constitutes a crime in and of itself as it disregards the fundamental principles of organ donation: respect for individuals, autonomy, consent, and altruism [17]. Essentially, there are many different definitions of OTC trafficking, however, in the 2009 document by the Joint Council of Europe and the United Nations [17] a functional definition is given:

"Trafficking in OTC occurs when there is (a) the illicit removal, preparation, preservation, storage, offering, distribution, brokerage, transport or implantation of organs, tissues or cells (cells for the purpose of therapeutic transplantation); and (b) the possession or purchase of organs, tissues or cells with a view to conducting one of the activities listed in (a); solely for financial or other economic gain (for this or a third person's benefit)"

The practice of treating organs as a commodity is defined as "transplant trade" and it is against the altruistic basis that characterizes organ donation.

THBOR and trafficking in OTC usually involve the transportation and transfer of individuals or organs, in a form of organ procurement known as transplant tourism. "Transplant tourism" refers to a journey for the purpose of a transplant which includes the movement of organs, donors, recipients, or specialised personnel for transplantation across jurisdictional borders for transplant purposes. 
Traveling for transplantation purposes becomes transplant tourism if it involves organ trafficking and/or the trade in transplants, or if the resources (organs, professionals, and transplant centres) dedicated to providing transplants for patients from a foreign country, compromise a state's ability to provide transplant services to its own population [15]. Transplant tourism is a complex phenomenon in which more elements are intertwined: the recruitment modalities, the movement of organ sellers and of the recipients, the location of testing and operating facilities make it all more difficult to outline the paths and borders of this practice, however, some general processes can be described.

More often than not, organ sellers - usually males, but in some instances a female prevalence has been observed $[1,10,17-19]$ - are recruited by brokers especially in destitute communities or they may find themselves in desperate situations, such as in the case of migrants that are in need of money [9,20-22]. This highlights the economic aspect behind organ trade since potential sellers are coerced or offered monetary retribution for selling their organs, carrying nevertheless the lifelong stigma and the potential health risks that the organ transplantation involves (Section 3) [17,23,24]. Brokers and recruiters do not act on their own, many other figures are present and the brokers themselves may be involved in many networks, determining the classification of organ trafficking as organised crime. For example, Italy and Nigeria find themselves to be the stage for the illegal operations carried out by the Nigerian mafia: evidence of illegal organ transplantations came to light especially in Castel Volturno and these allegations are currently being investigated by the Italian Procuratore Nazionale Antimafia [25]. In addition, legal and illegal health facilities identify, target, and report potential organ sellers to the brokers. Lastly, as previously mentioned, sham marriages may be a method of performing an illegal organ sale, meaning that organ vendors and recipients may agree to a fictitious short-term marriage so that the organ transaction can be concealed as an altruistic donation between partners [23], or, more in the framework of human trafficking, the victims may be misled by deceitful job prospects in foreign countries that further plunge them into debt $[10,18]$.

The brokers may implement different selling strategies, among which creating online advertisements on dedicated platforms or on social networks such as Twitter and Facebook [17,18,20]. For example, "transplant packages" are travel packages with all-inclusive fees to cover the transplantation journey and expenses (in addition to the hefty brokers' fees) [18]. Domestic or international travels to and accommodations at the location of the surgery may be arranged for the sellers as well, and they may be accompanied by other figures, such as minders or enforcers that guide the seller and make sure that the organ removal is followed through [10]. This movement of people that determines transplant tourism is characterised depending on who is travelling, where they come from, and where the surgery takes place, as described by Shimazono [18]: (a) the recipient may travel to the organ donor's home country, where the surgery is also taking place, (b) the seller travels to the recipient's country, where the surgery is performed, (c) donor and recipient come from the same country but the surgery is performed abroad, and (d) donor and recipient originate from different countries and they travel to a facility in a third country $[18,26]$. The Medicus Cases and the Netcare Cases are two prominent cases in which illegal kidney transplantation were successfully prosecutedalbeit only the Medicus Cases was treated as a human trafficking case - and they are two examples of the (d) mode of transplant tourism: in the first case, both sellers and recipients travelled to Kosovo, while in the latter, they travelled to facilities in South Africa $[10,12]$.

After being targeted and recruited, the sellers have to undergo tissue typing, blood testing for compatibility assessment, and, in the case of kidney transplants, urine testing [10,19,20,27]. Usually, these checks are carried out at different testing facilities, in order to speed the process up and increase the chances of identifying a match [20]. In addition, it is not uncommon that hospitals, nurses, and practitioners perform organ transplantations despite being aware that the donation has occurred behind compensation $[10,12,17,20,28]$, thus demonstrating the undeniable involvement of healthcare workers and medical staff with criminal activities. A striking example is given by the indictments in the above-mentioned Netcare Cases, where the entire medical facility was charged with illegal kidney transplantations $[10,12]$. Healthcare officials involved in illegal organ transplantations ignore good medical practice and they turn a blind eye to organ donations that are compelled by, as already mentioned, coercion, payment or other methods. In the so-called "organ laundering", the sellers sign paperwork and "informed consent" forms at the facility where the surgery is performed thus effectively concealing the illicit organ donation as an altruistic donation, and sheltering the medical centres from any criminal allegations [20,27]. The organ explantation and transplant are then performed, more or less willingly on the part of the seller $[12,19,20]$.

A fundamental aspect that deserves the utmost attention is the consideration that illicit organ trafficking has a tremendous impact on the lives and health of donors illegally sourced. The wellbeing of the donors is not of paramount importance to the traffickers and is often overlooked during research [5,6,9]. In addition, most donors receive little to no post-surgical medical care, leading to serious postoperative complications, often resulting in longterm effects on their health $[10,12,18,19,23]$. In some instances, the same is true for the recipients of the organs: due to the poor quality of the transplanted organs and the surgeries performed abroad, patients may end up with a malfunctioning organ in the less severe cases, while they may 
experience organ rejection or may contract blood-borne diseases in the more critical scenarios [6,29-31]. For example, after undergoing a kidney transplant in Iraq, Pakistan, and India, some patients have returned to their home countries reporting complications or blood-borne infections, such as hepatitis B [30]. In any case, there is a lack of reliable data on the percentages of kidney transplantation and survival of patients undergoing illicit transplants abroad, therefore it is difficult to precisely define the extent of the phenomenon.

Besides the obvious repercussion on the health of both donors and recipients, illegal organ donation heavily impacts their lives both socially and economically. Many sellers find themselves in an ambivalent position: many sell their organs under coercion and may consider themselves as victims, while others sell their organs of their own volition, however, they would face reprisals for deciding to not follow through with the organ explantation [10,20]. In addition, paid donors may not receive the initially agreed payment [10,20,23], and this, coupled with possible physically impairing surgery-related health problems, may exacerbate the individual's economic difficulties [18,19]. Socially, stigma and discrimination are associated with selling organs, meaning that there is shame and fear that prevent donors from reporting abuses and/or seeking treatment [10,12,20,27]. Likewise, recipients do not report their transplantations in fear of prosecution (since illegal organ transplantation is a crime) but, when the procedures are discussed in a court of law, they are often treated as witnesses, taking into consideration their deteriorated health status that led them to the decision of seeking organ transplant in an illegal manner [10,27]. The under-reporting combined with difficulties in investigating and prosecuting these crimes determines a very low number of prosecuted cases of organ trafficking [10-12]. In Annex A of the 2013 OSCE report [10], only 11 proceedings and 2 reported incidents are described, while in the UNODC Case Law database, hosted on SHERLOC, 16 cases are indexed under the keyword "Organ/tissue removal" and 14 under "Removal of organs" [11]. These numbers only represent a small fraction of the organ trafficking practices that take place worldwide, of which kidney transplantation is the most common type of surgery, herein taken into consideration.

\section{Kidney transplant}

Kidney transplantation is nowadays considered an established and successful standard medical procedure that, every year, improves the quality of life of thousands of patients. Kidney transplant is the most common type of solid organ transplant, with an estimated 100000 organs transplanted per year [8].

The European Renal Association's guidelines on kidney transplantation state that "all patients with end-stage disease should be considered for kidney transplantation unless they have absolute contraindications, as renal transplantation, compared to dialysis, offers a better life ex- pectancy and quality of life" [32,33]. For these reasons, kidney transplantation is now believed to have a more favourable cost-benefit than dialysis therapy.

Depending on the source of the organ, a kidney transplant is classified as a transplant from either a deceased or a living donor. Transplantation from deceased donors accounts for the majority of kidney transplants worldwide, taking however into consideration regional differences: it has been estimated that, for example, in Europe, $72.3 \%$ of kidney transplants are performed thanks to the donation from deceased individuals, while in the African continent kidneys from deceased donors account only for the $0.4 \%$ of transplants [8].

In Italy, kidney donations from people who have died as a result of direct damage to the brain (the so-called "brain death") are possible as long as the donor has expressed in life, in writing or verbally to family members, the will to donate organs after death or, if they did not manifest it, only when the family members do not oppose the removal [34]. This type of donation can be performed only after the ascertainment of death, which takes place following a carefully defined procedure and within a short lapse of time to ensure that the organs to be transplanted remain functional [35]. On the other hand, kidney transplantation from living individuals is possible given that one kidney alone may compensate for the missing counterpart and ensure normal health parameters. In Italy transplantation from living donors is regulated by Law no. 458 of June 26, 1967 [36]. People who want to be taken into consideration as kidney donors are subjected to rigorous clinical and instrumental health tests as well as accurate assessments of their psychic-psychological state to exclude that the organ donation could cause damage to the donor or to the patient who receives it. This also ensures that the will to donate is informed and free from conditioning [37].

To reduce the risk of rejection, the majority of living organ donations were made by the recipient's close relatives, who are more likely to share genetic characteristics and blood type, however, allografts from unrelated living donors are increasingly performed, after evaluation of functional physiological indices, psychic integrity and the ability to provide informed consent $[37,38]$. In addition, postsurgical treatments with immunosuppressive drugs to prevent rejection by the immune system are, in fact, extremely effective even when the donors are not genetically similar to the recipients, thus increasing the possibility of using living donors [39].

Prognosis after kidney transplantation is generally excellent, with survival rates ranging from $80 \%$ to $95 \%$, up to $97 \%$ one-year survival rate for the patients [40], and transplantation from a living donor seems to have a greater chance of long-term success than transplantation from a deceased donor [40]. 


\section{The possible role of legal medicine and forensic genetics in fighting illegal organ trafficking}

\subsection{Routine casework technologies in forensic genetics}

Normally, genetic investigations carried out in the forensic context for individual identification are strictly based on comparative bases: DNA profiles obtained from biological material found at crime scenes, in cases of missing persons or mass disasters, are compared with those of individuals of interest or their relatives [41]. If compatibility between biological sample and reference profile is demonstrated, then it is possible to establish the identity of the subject [42]. Otherwise, if there isn't genetic compatibility between the DNA profiles, the identification of the subject or the establishment of kinship relationships are excluded.

In cases where no reference DNA profile is available, the genetic markers normally employed in forensic DNA profiling cannot provide any useful information for identification purposes. For this reason, the international scientific community has, in recent years, focused its attention on new specific genetic markers for the prediction of phenotypic traits, known as Externally Visible Characteristics (EVCs, such as the colour of the eyes, hair, or skin) and Biogeographic Ancestry (BGA) of unidentified subjects [43-45]. Investigations of this type once validated for forensic use, can be introduced as a routine analysis within the forensic genetics laboratory and provide excellent support for the investigative activity. Thus, it will be possible to focus police investigations against specific groups of people and reduce the number of potential suspects to be typed through conventional DNA analysis.

Further advancement in this field is represented by the development of technologies and methodologies appropriate for the study of Single Nucleotide Polymorphisms (SNPs) panels $[43,45,46]$.

Single Nucleotide Polymorphisms (SNPs) have proved very useful in the forensic genetics laboratory as a complement to the normal investigations conducted through STRs (Short Tandem Repeats) polymorphisms, especially in the analysis of very degraded samples and in complex parental assessment tests, as well as in the analysis of phenotypic traits and in the identification of the Biogeographic Ancestry through AIMs-Indels (Ancestry Informative Markers) and Ancestry Informative STRs [43-45,47]. The advantages of STR markers is that they are cost-effective, and the personnel usually has extensive expertise and training in their analysis, resulting in their wider acceptability in courtrooms. For the application in BGA predictions, in fact, STRs are evaluated using Bayesian methods that assess the strength of the hypothesis, expressed as a Likelihood Ratio, that an individual belongs to a specific geographic area rather than another [48]. However, STRs marker are less informative for BGA inference due to their mutational instability which produces a high variability within a population but a relatively low variability among different populations, resulting in error percentages higher than SNPs $[48,49]$. In addition, other STRs' limitations reside in the DNA mixtures interpretation, in the definition of population clusters $[48,50]$, and in the absence of software with userfriendly graphic interfaces, resulting in the development and employment of multivariate statistical approaches (Multivariate Data Analysis) for STRs analysis for the estimation of geographic origin [48].

On the other hand, SNPs have become the gold standard for BGA inference since genetic ancestry is a characteristic defined by broadly based continental population group's SNPs variability $[45,46]$. In addition, despite their limitations, such as their cost, the fact that some laboratories may not be equipped to work with SNPs, and the need for specific statistical and bioinformatic approaches for their analysis, SNPs are analysed with different strategies and software, as STRUCTURE and Snipper [51,52].

For geographic origin estimation, substantial information has been massively collected. At the Jean DaussetCentre d'Etude du Polymorphisme Humain (CEPH) [53] Foundation in Paris, there are 1063 lymphoblastoid cell lines from 1050 individuals belonging to 52 different populations around the world. These cell lines have been collected from laboratories around the world as part of the Human Genome Diversity Project (HGDP) [54]. This is a project initiated by the Morrison Institute of Stanford University with the collaboration of scientists from all over the world. The scientific community used HGDP data to study human migration, gene mutation rates, relationships between different populations, and genes undergoing selection. Stanford's HGDP-CEPH studies were instrumental in evaluating human diversity in genetic terms, providing information on similarities and differences between the populations that inhabit the five continents. Using these cell lines whose geographical origin was known, numerous studies were carried out to identify panels of markers (SNPs) suitable for determining the geographical origin of a subject $[45,46]$.

As for the methods employed, BGA prediction may be carried out through Single Base Extension analysis of Ancestry Informative SNPs (aiSNPs), however, in recent years, Massive Parallel Sequencing BGA Panels have been developed. This technology permits the simultaneous typing of an increased number of SNPs, thus (i) reducing the time required to perform the analysis, (ii) allowing to more accurately pinpoint the region of origin of an individual, and (iii) allowing to couple BGA and EVCs prediction. This can be particularly useful for those individuals with mixed ancestry background, as autosomal, mtDNA and Y chr SNPs [55], can be analysed at the same time, yielding more information. mtDNA and Ychr SNPs carry information on the matrilineal and patrilineal ancestries. Among the panels available, there is the ForenSeq ${ }^{\mathrm{TM}}$ DNA Signature Prep 
Kit (Verogen, USA), which includes 56 autosomal aiSNPs that allow discriminating between four continental regions (Europe, Africa, America and East Asia) [55-57]. The Precision ID Ancestry Panel (ThermoFisher Scientific, USA) allows the analysis of 165 autosomal aiSNPs in relation to seven continental regions (sub-Saharan Africa, the Americas, East Asia, Europe, Oceania, South Asia, Southwest Asia) $[55,58,59]$. Recently, the VISAGE Consortium, developed and is validating both a basic and an advanced tool for EVCs, BGA, and Age prediction. As for BGA inference, 153 aiSNPs are analysed in a single multiplex reaction [60]. Other SNPs panels for forensic human identification are commercially available [61-63].

\subsection{The application of ancestry-informative genetic marker analysis as a scientific tool to combat the illegal traffic in human kidneys}

The analytical tools routinely used in forensic investigations may be employed for the identification of the unknown donor of an organ illegally acquired, representing an innovative sector of forensic genetics, unconventional but of great social impact nevertheless [64].

Evidence shows that the victims, from whom organs are illegally harvested, and the receivers of the organs may come from genetically distinct populations. "Sellers" traditionally originate mainly from China, Pakistan, Egypt, India, the Philippines, and Colombia. Recently Kosovo, South Africa, Latin America, and Brazil have been added to the list. The "buyers" are mostly from the United States of America, the Gulf countries, Israel, Japan, Australia, and Canada $[1,2,5,6]$.

Given this difference, the introduction of a forensic genetic genealogy test included in the normal posttransplant control follow-up could be useful to highlight the geographical origin of the individual from whom the kidney was explanted. This type of analysis may be particularly useful in those instances in which there are no existing records of a transplantation surgery for the patient and the organ donor is not known. In some countries, such as Sweden, the Netherlands, and the UK, anonymous organ transplants are performed $[65,66]$, however, comprehensive medical records and donor registries are nonetheless available and all transplants are registered. Therefore, the analysis of aiSNPs and the donor's BGA inference would provide a beneficial tool in cases where the identity of the donor is not clearly indicated. This would allow authorities to gather further information on the extent of illicit kidney trafficking and on possible trafficking routes, thus more effectively countering this ignoble practice.

In the context of renal transplantation, the biological rationale behind the determination of an organ donors' BGA is the observation that the urine of the recipient subject contains cells both from the donor, which derive essentially from the transplanted kidney, and from the recipient's own lower urinary tract $[64,67]$. Additionally, given the
SNPs variability between continental populations [68] and the development of technologies and methodologies for the study of panels of SNPs, some authors developed the idea of establishing genetic tests capable of differentiating the geographic origin of the two cell populations detectable in the urine of persons who have received a kidney transplant.

In a recent multicentre study [64], a total of 92 patients who had undergone a kidney transplant, were recruited at the Transplant Centre of the Azienda Ospedaliera Universitaria "Santa Maria Delle Scotte" in Siena, Italy (57 patients), and at the Nephrology Centre of the Hospital Clìnico Universitario in Santiago De Compostela, Spain (35 patients). Each patient provided a urine sample and an oral swab as a reference sample for the correct recipient's genotype. DNA from urine samples was extracted and both urine and reference samples were analysed with the 34plex assay using PCR and Single Base Extension (SBE) primers described by Fondevila et al. [46]. All of the urine samples produced a dual genetic profile, thus confirming that the genetic analysis of a urine sample is a viable option for the determination of the geographical origin of both the donor and the recipient of a transplanted kidney. These results are particularly encouraging and evident in those cases in which donor and recipient are of different geographic areas.

Given that many up to date and comprehensive aiSNPs MPS Panels are commercially available [56-63], and considering the promising results obtained by the aforementioned study, it would interesting and of immense usefulness to perform studies of similar nature using Next Generation Sequencing for BGA inference in the field of kidney transplantations. It is important to point out that, despite the obvious advantages of SNPs analysis in respect to STRs analysis in the particular instance of Biogeographic Ancestry, mixture detection and deconvolution of SNPs profiles pose more difficulties than STR analysis, which in turn, allows for a greater resolution between the contributors to the mixtures. In any case, SNPs mixture deconvolution is feasible, albeit difficult $[69,70]$, and in the case of kidney transplantations some considerations have to be made: (i) the DNA mixture cannot be composed of more than two contributors; (ii) the reference profile of the organ recipient is known, therefore, the mixture can be analysed accordingly, for example, by using EuroForMix [69]; (iii) if the geographic ancestry of the donor and of the recipient were to be similar and not discriminating enough, this would be useful information anyhow, since the purpose of the application this technique would be to broadly determine the region of origin of an organ donor.

In any case, aiSNPs analysis through SBE techniques, such as in the study by Severini and colleagues [64] is feasible and of easy implementation in any forensic genetics laboratories that are already equipped for SNPs analysis or, in any case, it would not necessarily require the purchase of expensive equipment that might not be available to them, therefore making SBE methods a practical technique apt for 
widespread use.

\section{Conclusions}

Illicit organ trafficking has a high cost in terms of health and quality of the lives of those involved. First and foremost, the donors, who are coerced into selling their organs, are subjected to an appalling form of human trafficking and they face direct and serious health risks, that are often overlooked $[1,2,5,6,8]$. Secondly, the quality of the transplantation does not necessarily directly affect the posttransplant conditions of the patient. Nonetheless, some nephrologists argued that the poor quality of both the kidneys and the transplant surgeries performed abroad may cause critical complications or infections [6,29,30]. However, the rates of successful grafts and survival of patients who underwent commercial transplants overseas are not documented, so it is difficult to obtain a reliable and valid perspective of said transplants' outcomes.

Currently, regenerative medicine, which uses advanced cellular and genetic therapies aimed at the reconstruction of irreversibly damaged tissues and organs, could represent a possible solution to the shortage of organ donors. Encouraging results have recently been achieved using populations of adult stem cells present in the same tissues to be regenerated and it can be said that experimentation in the field of tissue engineering aimed at organogenesis to synthesize parts of organs is already at an advanced stage [67].

Recently, for the first time, a group of scientists succeeded in producing human embryonic stem cells (hESCs) using the nuclear transfer technique [71]. Somatic cell nuclear transfer (SCNT) is a technique in which the nucleus of a donor cell is transferred to an egg cell whose nucleus has been previously removed, generating embryonic cells that are genetically identical to those of the donor except for, clearly, mitochondrial DNA.

This technique of producing specific stem cells for a patient is an alternative to that of induced pluripotent stem cells (iPS) [71] which are generated directly from the patient's somatic cells with the addition of a cocktail of cellular factors capable of stimulating their regression to a state of stem cell. The advantage represented by the nuclear transfer technique over that of the induction of pluripotent stem cells is above all that of overcoming the major drawback represented by the possible unexpected and unwanted mutations that can occur with the use of iPS cells. In fact, from the studies that have been carried out, it seems that nuclear transfer can "reset" the epigenetic identity of the somatic cells more efficiently used. "These stem cells can regenerate and replace damaged cells and tissues and alleviate diseases that affect millions of people", said Shoukhrat Mitalipov of Oregon Health \& Science University, who led the research, the results of which are published in the journal "Cell" [71].
Besides the help that science will be able to provide in the near future, today the worldwide eradication of the exploitation of vulnerable subjects and the horrific organ market would require strong joint action of individual nations. This action could be implemented through the application of all the measures provided and recommended in the United Nations Convention against transnational organized crime signed during the Palermo Conference as early as December 2000 [7]. In addition, each country should implement educational and health policy programs to prevent the lack of organs for transplantation to satisfy the internal demand of the population and, above all, to encourage the voluntary donation of organs, tissues, and cells in the event of death. From a legislative point of view, the fight against this form of illegality should tackle both human trafficking and OTC trafficking and should include the prohibition of all types of advertising (both on the web and the press) that solicit or encourage intermediation for trade in transplants, trafficking in organs, or transplant tourism. In addition, there should also be sanctions for acts-such as medical screening of donors or organs, or organ transplantationthat enable, encourage, or use products of organ trafficking or transplant tourism.

As for forensic genetics, the high quality of data produced by current forensic genetics analytical techniques justifies the choice of a study design aimed at applying tools capable of bringing this trade to light, inserting it in the broader context of counteracting the trafficking of persons. The hypothesized and envisioned role that forensic medicine could assume in the fight against illegal kidney trafficking could consist in the genetic characterization of the urine samples of follow-up patients whose clinical history is unclear. Said characterization would be carried out by using identification techniques consolidated in the forensic genetics laboratory.

However, this type of investigation raises questions and needs evaluations in the bioethical field.

In the Italian context, for example, a first assessment concerns the application of article 365 of the criminal code (Omission of report). Said article obligates doctors, physicians, and healthcare professionals to inform the Judicial Authority when, while exercising their profession, they become aware of facts or details of an offense that can be prosecuted ex officio. Failing of this will result in the payment of a fine. The exemption from the reporting obligation is provided only if the described facts could expose the patient to criminal proceedings.

An even more stringent second assessment can be found in the Italian and European legislation on the processing of personal data (Articles 13 and 14 of EU Reg. 2016/679) which provides specific rules for the processing of sensitive data, including health and genetic data. In the light of this legislation, the main ethical assessment concerns the possibility of performing genetic analysis on urine samples collected during the post-transplant follow-up. In 
fact, as of today, patients give their informed consent for the analysis of their samples with the sole purpose of monitoring clinical aspects and parameters. In particular, any other medical and genetic investigations must be authorized by the patient who must provide written consent after being fully informed of the purposes and methods of the proposed investigation. This informed consent represents the foundation of the lawfulness of the healthcare activity, in the absence of which the activity itself constitutes a crime. The doctor or healthcare professional is also required to make sure that the patient has correctly understood the provided information.

The analysis of anonymized urine samples may solve such ethical issues, as the privacy of the patients would be protected, yet the genetic investigation could be carried out. Therefore, illegal transplants may be detected, thus allowing the monitoring of the criminal phenomenon, an essential prerequisite for any attempt to limit or contrast illicit trafficking of organs. At the same time, the comparison of the data obtained from said urine samples with the published data relating to the frequencies of genetic markers, suitable for identifying an individual's geographical origin, would not entail any kind of ethical problems since the allele frequencies are related to anonymous data.

Additionally, if missing person databases are present in the countries targeted by illicit trafficking of organs, genetic investigations could be deepened to identify unknown organ donors. This means that, once the geographical region of the donor has been identified on a continental level, a subsequent step could be represented by the comparison of the donor's genetic profile with the missing persons databases of the affected nations included in the region inferred by BGA analysis. In this case as well, there would be no ethical issues involved since the necessary consent would be acquired at the time of the introduction of the missing person's sample in the database. Moreover, such databases have a completely different purpose and rules from those concerning the forensic databases that are set up in many countries: the latter, in fact, have the judicial purpose of providing valuable elements in the resolution and prevention of crimes. Nevertheless, this prospect is optimistic and wishful thinking, since it would require a joint effort on the part of the single affected nations for the establishment of national missing persons databases and for the fight against organ trafficking as a result of THBOR and of OTC trafficking.

We believe that National and International laws and collaborations, both humanitarian and academic, are necessary to create a redundant, feedback control system not only at the transplant stage but also during the post-operative follow-up, particularly in cases of patients without a clear clinical history that may have received an organ transplantation in a foreign country. We are also of the opinion that, at the present time, forensic medicine may supply strong evidence and leads in regard to organ transplantation. Recent studies [64] demonstrated that DNA typing techniques are applicable in the specific case of kidneys transplantation for the determination of the DNA profile of both donor and recipient of the organ, so that so STRs and SNPs panels apt for Biogeographic Ancestry determination may represent fundamental resources in the fight against organ trafficking, particularly in cases of dubious origin of organs or in transplantation cases in which clear and comprehensive medical records of both patients and donors are not available.

\section{Author contributions}

EC, SS and GM designed the literature research and wrote the manuscript. SS performed the research. MO wrote and edited the paper. CG, LC and MB provided help and advice on the research material. All authors contributed to editorial changes in the manuscript. All authors read and approved the final manuscript.

\section{Ethics approval and consent to participate}

Not applicable.

\section{Acknowledgment}

Not applicable.

\section{Funding}

This research received no external funding.

\section{Conflict of interest}

The authors declare no conflict of interest.

\section{References}

[1] United Nation Office on Drugs and Crime, UNODC. Global Report on Trafficking in Person. 2018. Available at: https://www.unodc.org/documents/data-and-analysis/glotip /2018/GLOTiP_2018_BOOK_web_small.pdf (Accessed: 13 January 2022).

[2] United Nation Office on Drugs and Crime, UNODC. Global Report on Trafficking in Person. 2020. Available at: https://www.unodc.org/documents/data-and-analysis/tip/2021/ GLOTiP_2020_15jan_web.pdf (Accessed: 13 January 2022).

[3] Prevention of and Fight against Crime Programme of the European Union. HESTIA Project: "Preventing human trafficking and sham marriages: A multidisciplinary solution"-Agreement N. HOME/2013/ISEC/AG/THB/4000005845. 2016. Available at: http://cilvektirdznieciba.lv/uploads/files/hestia_methodical_ material_eng.pdf (Accessed: 13 January 2022).

[4] European Roma Rights Centre. Breaking the Silence: Trafficking in Romani Communities. 2011. Available at: http://www.errc.org/uploads/upload en/file/breaking-the-silen ce-19-march-2011.pdf (Accessed: 13 January 2022).

[5] Global Financial Integrity. Transnational Crime and the Developing World. 2017. Available at: https://gfintegrity.org/report /transnational-crime-and-the-developing-world/ (Accessed: 13 January 2022).

[6] European Parliament, Directorate-General For External Policies - Policy Department. Trafficking in human organs. 2015. Available at: https:/www.europarl.europa.eu/RegData/etude s/STUD/2015/549055/EXPO_STU(2015)549055_EN.pdf (Accessed: 13 January 2022). 
[7] Protocollo addizionale della Convenzione delle Nazioni Unite contro la criminalità organizzata transnazionale per prevenire, reprimere e punire la tratta di persone, in particolare di donne e bambini (Palermo, 12-15 dicembre 2000). 2000. Available at: https://www.admin.ch/opc/it/federal-gazette/2005/6067.pdf (Accessed: 13 January 2022).

[8] Global Observatory on Donation and Transplantation. Internal Report on Organ Donation and Transplantation Activities. 2021. Available at: http://www.transplant-observatory.org/w p-content/uploads/2021/06/GODT2019-data_web_updated-J une-2021.pdf (Accessed: 13 January 2022).

[9] Gonzalez J, Garijo I, Sanchez A. Organ Trafficking and Migration: A Bibliometric Analysis of an Untold Story. International Journal of Environmental Research and Public Health. 2020; 17: 3204.

[10] OSCE Office of the Special Representative and Co-ordinator for Combating Trafficking in Human Beings. Trafficking in $\mathrm{Hu}-$ man Beings for the Purpose of Organ Removal in the OSCE Region: Analysis and Findings, Occasional Paper Series no. 6. 2013. Available at: https://www.osce.org/files/f/documents/e/b /103393.pdf (Accessed: 13 January 2022).

[11] United Nations Office on Drugs and Crime. Case Law Database, hosted on SHERLOC. 2021. Available at: https://sherloc.unodc. org/cld/v3/htms/cldb/index.html?lng=en (Accessed: 13 January 2022).

[12] Ambagtsheer F. Understanding the challenges to investigating and prosecuting organ trafficking: a comparative analysis of two cases. Trends in Organized Crime. 2021. (in press)

[13] Assemblea Mondiale della Sanità, AMS. Risoluzione 44.25. GU dell'Unione Europea ISSN 1725-2466 del 26-04-2003. 2003. Available at: https://eur-lex.europa.eu/legal-content/IT/TXT/ PDF/?uri=OJ:C:2003:100:FULL\&from=IT (Accessed: 13 January 2022).

[14] World Health Organization. $57^{t h}$ World Health Assembly Resolution 57.18 - Human organ and tissue transplantation. 2004. Available at: http://www.who.int/gb/ebwha/pdf_files/WHA57/ A57_R18-en.pdf (Accessed: 13 January 2022).

[15] Declaration of Istanbul. Istanbul Summit on Organ Trafficking and Transplant Tourism (Istanbul, 2008). 2008. Available at: http://www.fondazioneitalianadelrene.org/wp-content/uploa ds/2010/09/Dichiaraz ISTAMBUL Italiano.pdf (Accessed: 13 January 2022).

[16] Council of Europe. Council of Europe Convention against Trafficking in Human Organs CETS n.216 Santiago De Compostela 2015, march, 25. 2015. Available at: https://rm.coe.int/16806d ca3a (Accessed: 13 January 2022).

[17] Joint Council of Europe/United Nations Study. Trafficking in organs, tissues and cells and trafficking in human beings for the purpose of the removal of organs. 2009. Available at: https: //rm.coe.int/16805ad1bb (Accessed: 13 January 2022).

[18] Shimazono Y. The state of the international organ trade: a provisional picture based on integration of available information. Bulletin of the World Health Organization. 2007; 85: 955-962.

[19] Goyal M, Mehta RL, Schneiderman LJ, Sehgal AR. Economic and Health Consequences of Selling a Kidney in India. The Journal of the American Medical Association. 2002; 288: 15891593.

[20] Columb S. Excavating the Organ Trade: An Empirical Study of Organ Trading Networks in Cairo, Egypt. The British Journal of Criminology. 2017; 57: 1301-1321

[21] Nossiter A and Rahim N. In Afghanistan, a Booming Kidney Trade Preys on the Poor. The New York Times. 2021. Available at: https://www.nytimes.com/2021/02/06/world/asia /selling-buying-kidneys-afghanistan.html (Accessed: 13 January 2022).

[22] Baraaz T. Illegal Organ Harvesting Is Rampant in Egypt, and Refugees Are the Main Target. Haaretz. 2018. Available at: https://www.haaretz.com/middle-east-news/egypt/.premium .MAGAZINE-illegal-organ-harvesting-is-rampant-in-egypt -and-refugees-are-the-main-target-1.6492013 (Accessed: 13 January 2022).

[23] Kelly E. International Organ Trafficking Crisis: Solutions Addressing the Heart of the Matter, 54 B.C. L. Rev. 1317. 2013. Available at: https://lawdigitalcommons.bc.edu/bclr/vol54/iss3/ 17 (Accessed: 13 January 2022).

[24] Glaser SR. Formula to Stop the Illegal Organ Trade: Presumed Consent Laws and Mandatory Reporting Requirements for Doctors, 12 HuM. RTS. BRIEF 20, 20. 2005. Available at: https://digitalcommons.wcl.american.edu/hrbrief/ vol12/iss2/6/ (Accessed: 13 January 2022).

[25] Dalla Casa S. Realtà e leggenda del traffico d'organi. Wired. 2019. Available at: https://www.wired.it/play/cultura/2019/01/ 12/leggende-traffico-organi/ (Accessed: 13 January 2022).

[26] Budiani-Saberi DA, Delmonico FL. Organ trafficking and transplant tourism: a commentary on the global realities. American Journal of Transplantation. 2008; 8: 925-929.

[27] Manzano A, Monaghan M, Potrata B, Clayton M. The invisible issue of organ laundering. Transplantation. 2014; 98: 600-603.

[28] Sahi MK, Shroff S, Navin S, Kumar P. Organ commercialism, trafficking and transplant tourism. Indian Journal of Medical Ethics. 2021. (in press)

[29] Babik JM, Chin-Hong P. Transplant tourism: understanding the risks. Current Infectious Disease Reports. 2015; 17: 473.

[30] Sajjad I, Baines LS, Patel P, Salifu MO, Jindal RM. Commercialization of kidney transplants: a systematic review of outcomes in recipients and donors. American Journal of Nephrology. 2008; 28: 744-754.

[31] Morris MI, Muller E. Infectious Complications of Transplant Tourism. Current Infectious Disease Reports. 2019; 21: 36.

[32] Società Italiana di Urologia, SIU, European Association of Urology, EAU. Guidelines on renal transplant. 2019. Available at: https://www.siu.it/linee-guida/non-oncologiche/2018\%20n on\%20oncologiche/sul-trapianto-renale (Accessed: 13 January 2022).

[33] Abramowicz D, Cochat P, Claas FH, Heemann U, Pascual J, Dudley C, et al. European Renal Best Practice Guideline on kidney donor and recipient evaluation and perioperative care. Nephrology Dialysis Transplantation. 2015; 30: 1790-1797.

[34] Disposizioni in materia di prelievi e di trapianti di organi e di tessuti. Legge n. 91 del 1 aprile del 1999. GU Serie Generale n. 87 del 15-04-1999. 1999. Available at: https://www.gazzetta ufficiale.it/eli/gu/1999/04/15/87/sg/pdf (Accessed: 13 January 2022).

[35] Norme per l'accertamento e la certificazione di morte. Legge n. 578 del 29 dicembre 1993. GU Serie Generale n. 5 del 08-011994. 1994. Available at: https://www.gazzettaufficiale.it/eli/g u/1994/01/08/5/sg/pdf (Accessed: 13 January 2022).

[36] Trapianto del rene tra persone viventi. Legge n. 458 del 26 giugno 1967. GU Serie Generale n. 160 del 27-06-1967. 1967. Available at: https:/www.normattiva.it/uri-res/N2Ls?urn:nir:st ato:legge:1967-06-26;458G (Accessed: 13 January 2022).

[37] Ahmad N, Ahmed K, Khan MS, Calder F, Mamode N, Taylor J, et al. Living-Unrelated Donor Renal Transplantation: an Alternative to Living-Related Donor Transplantation? The Annals of the Royal College of Surgeons of England. 2008; 90: 247-250.

[38] Istituto Superiore della Sanità. Salute dalla A alla Z - Trapianto di rene. Available at: https://www.issalute.it/index.php/la-sal ute-dalla-a-alla-z-menu/t/trapianto-di-rene (Accessed: 13 January 2022).

[39] Schinstock CA, Mannon RB, Budde K, Chong AS, Haas M, Knechtle S, et al. Recommended Treatment for Antibodymediated Rejection after Kidney Transplantation: the 2019 Expert Consensus from the Transplantion Society Working Group. Transplantation. 2020; 104: 911-922. 
[40] Istituto Superiore della Sanità, Centro Nazionale Trapianti. Valutazione di Qualità dell'Attività del Trapianto del Rene 20002019. 2021. Available at: https://www.trapianti.salute.gov.it/ imgs/C_17_cntPubblicazioni_409_allegato.pdf (Accessed: 13 January 2022).

[41] Prinz M, Carracedo A, Mayr WR, Morling N, Parsons TJ, Sajantila A, et al. DNA Commission of the International Society for Forensic Genetics (ISFG): Recommendations regarding the role of forensic genetics for disaster victim identification (DVI). Forensic Science International: Genetics. 2007; 1: 3-12.

[42] Turchi C, Previderè C, Bini C, Carnevali E, Grignani P, Manfredi A, et al. Assessment of the Precision ID Identity Panel kit on challenging forensic samples. Forensic Science International: Genetics. 2020; 49: 102400.

[43] Kayser M. Forensic DNA Phenotyping: Predicting human appearance from crime scene material for investigative purposes. Forensic Science International. Genetics. 2015; 18: 33-48.

[44] Phillips C. Forensic genetic analysis of bio-geographical ancestry. Forensic Science International: Genetics. 2015; 18: 49-65.

[45] Phillips C, Salas A, Sánchez JJ, Fondevila M, Gómez-Tato A, Álvarez-Dios $\mathrm{J}$, et al. Inferring ancestral origin using a single multiplex assay of ancestry-informative marker SNPs. Forensic Science International: Genetics. 2007; 1: 273-280.

[46] Fondevila M, Phillips C, Santos C, Freire Aradas A, Vallone PM, Butler JM, et al. Revision of the SNPforID 34-plex forensic ancestry test: Assay enhancements, standard reference sample genotypes and extended population studies. Forensic Science International: Genetics. 2013; 7: 63-74.

[47] Margiotta G, Iacovissi E, Severini S, Tommolini F, Carnevali E. Forensic DNA Phenotyping: a new powerful tool in Forensic Medicine. In Margiotta G, Iacovissi E, Severini S, Tommolini F, Carnevali E, Kinoshita H, et al. (ed.) Forensic Medicine: Fundamentals, Clinical Perspectives and Challenges (pp. 1-22). New York: Edith J. Hammond. 2016.

[48] Alladio E, Della Rocca C, Barni F, Dugoujon J, Garofano P, Semino $\mathrm{O}$, et al. A multivariate statistical approach for the estimation of the ethnic origin of unknown genetic profiles in forensic genetics. Forensic Science International: Genetics. 2020; 45: 102209 .

[49] Fondevila M. Challenging DNA: Assessment of a range of genotyping approaches for highly degraded forensic samples. Forensic Science International: Genetics Supplement Series. 2008; 1: 26-28.

[50] Alladio E, Omedei M, Cisana S, D'Amico G, Caneparo D, Vincenti M, et al. DNA mixtures interpretation - a proof-of-concept multi-software comparison highlighting different probabilistic methods' performances on challenging samples. Forensic Science International: Genetics. 2018; 37: 143-150.

[51] Moriot A, Santos C, Freire-Aradas A, Phillips C, Hall D. Inferring biogeographic ancestry with compound markers of slow and fast evolving polymorphisms. European Journal of Human Genetics. 2018; 26: 1697-1707.

[52] de la Puente M, Ruiz-Ramírez J, Ambroa-Conde A, et al. Development and Evaluation of the Ancestry Informative Marker Panel of the VISAGE Basic Tool. Genes. 2020; 12: 1284.

[53] Dausset J, Cann H, Cohen D, Lathrop M, Lalouel JM, White R. Centre d'etude du polymorphisme humain $(\mathrm{CEPH})$ : collaborative genetic mapping of the human genome. Genomics. 1990; 6 : 575-577.

[54] Foundation Jean Dausset. 2020. HGDP-CEPH Allelic Frequency Database v3.0. Available at: https://cephb.fr/en/hgdp/h gdp_search.php (Accessed: 13 January 2022).

[55] Schneider PM, Prainsack B, Kayser M. The Use of Forensic DNA Phenotyping in Predicting Appearance and Biogeographic Ancestry. Deutsches Ärzteblatt International. 2019; 5152: $873-880$.
[56] Jäger AC, Alvarez ML, Davis CP, Guzmán E, Han Y, Way $\mathrm{L}$, et al. Developmental validation of the MiSeq FGx Forensic Genomics System for Targeted next Generation Sequencing in Forensic DNA Casework and Database Laboratories. Forensic Science International: Genetics. 2017; 28: 52-70.

[57] Frégeau CJ. Validation of the Verogen ForenSeq ${ }^{\mathrm{TM}}$ DNA Signature Prep kit/Primer Mix B for phenotypic and biogeographical ancestry predictions using the Micro MiSeq ${ }^{\circledR}$ Flow Cells. Forensic Science International: Genetics. 2021; 53: 102533.

[58] Jin S, Chase M, Henry M, Alderson G, Morrow JM, Malik S, et $a l$. Implementing a biogeographic ancestry inference service for forensic casework. Electrophoresis. 2018; 39: 2757-2765.

[59] Pereira V, Mogensen HS, Børsting C, Morling N. Evaluation of the Precision ID Ancestry Panel for crime case work: a SNP typing assay developed for typing of 165 ancestral informative markers. Forensic Science International: Genetics. 2017; 28: $138-145$.

[60] Xavier C, de la Puente M, Mosquera-Miguel A, Freire-Aradas A, Kalamara V, Vidaki A, et al. Development and validation of the VISAGE AmpliSeq basic tool to predict appearance and ancestry from DNA. Forensic Science International: Genetics. 2020; 48: 102336.

[61] Guo F, Zhou Y, Song H, Zhao J, Shen H, Zhao B, et al. Next generation sequencing of SNPs using the HID-Ion AmpliSeqTM Identity Panel on the Ion Torrent PGM ${ }^{\mathrm{TM}}$ platform. Forensic Science International: Genetics. 2016; 25: 73-84.

[62] de la Puente M, Phillips C, Santos C, Fondevila M, Carracedo Á, Lareu MV. Evaluation of the Qiagen 140-SNP forensic identification multiplex for massively parallel sequencing. Forensic Science International: Genetics. 2017; 28: 35-43.

[63] Guo F, Yu J, Zhang L, Li J. Massively parallel sequencing of forensic STRs and SNPs using the Illumina ${ }^{\circledR}$ ForenSeq ${ }^{\mathrm{TM}}$ DNA Signature Prep Kit on the MiSeq FGx ${ }^{\mathrm{TM}}$. Forensic Genomics System. Forensic Science International. Genetics. 2017; 31: $135-148$.

[64] Severini S, Carnevali E, Margiotta G, Garcia-González MA, Carracedo A. Use of ancestry-informative markers as a scientific tool to combat the illegal traffic in human kidneys. Forensic Science International: Genetics Supplement Series. 2015; 5: e302-e304.

[65] Khetpal V, Mossialos E. An ethical appraisal of livinganonymous kidney donation using Adam Smith's Theory of Moral Sentiments. Health Policy. 2018; 122: 1212-1221.

[66] Slaats D, Lennerling A, Pronk MC, van der Pant KAMI, Dooper IM, Wierdsma JM, et al. Donor and Recipient Perspectives on Anonymity in Kidney Donation from Live Donors: a Multicenter Survey Study. American Journal of Kidney Diseases. 2018; 71: $52-64$

[67] Larouche D, Lavoie A, Proulx S, Paquet C, Carrier P, Beauparlant $\mathrm{A}$, et al. Regenerative medicine: stem cells, cellular and matricial interactions in the reconstruction of skin and cornea by tissue engineering. Pathologie-Biologie. 2009; 57: 299-308.

[68] Zhang J, Tong KL, Li PK, Chan AY, Yeung CK, Pang CC, et al. Presence of donor- and recipient-derived DNA in cell-free urine samples of renal transplantation recipients: urinary DNA chimerism. Clinical Chemistry. 1999; 45: 1741-1746.

[69] Bleka Ø, Eduardoff M, Santos C, Phillips C, Parson W, Gill P. Open source software EuroForMix can be used to analyse complex SNP mixtures. Forensic Science International: Genetics. 2017; 31: 105-110.

[70] Pascali VL. A novel computational strategy to predict the value of the evidence in the SNP-based forensic mixtures. PLoS ONE. 2021; 16: e0247344.

[71] Tachibana M, Amato P, Sparman M, Gutierrez N, TippnerHedges R, Ma H, et al. Human Embryonic Stem Cells Derived by Somatic Cell Nuclear Transfer. Cell. 2013; 153: 1228-1238. 